Regular Article

\title{
Innovative chemical gels meet enzymes: A smart combination for cleaning paper artworks
}

\author{
Claudia Mazzuca ${ }^{\mathrm{a}}$, Giovanna Poggi ${ }^{\mathrm{b}}$, Nicole Bonelli ${ }^{\mathrm{b}}$, Laura Micheli ${ }^{\mathrm{a}}$, Piero Baglioni ${ }^{\mathrm{b}}$, Antonio Palleschi ${ }^{\mathrm{a}, *}$ \\ a Department of Chemical Sciences and Technologies E' CSGI, University of Rome "Tor Vergata", Via della Ricerca Scientifica 1, 00133 Rome, Italy \\ ${ }^{\mathrm{b}}$ Department of Chemistry \&' CSGI, University of Florence, Via della Lastruccia 3 - Sesto Fiorentino, 50019 Florence, Italy
}

\section{G R A P H I C A L A B S T R A C T}

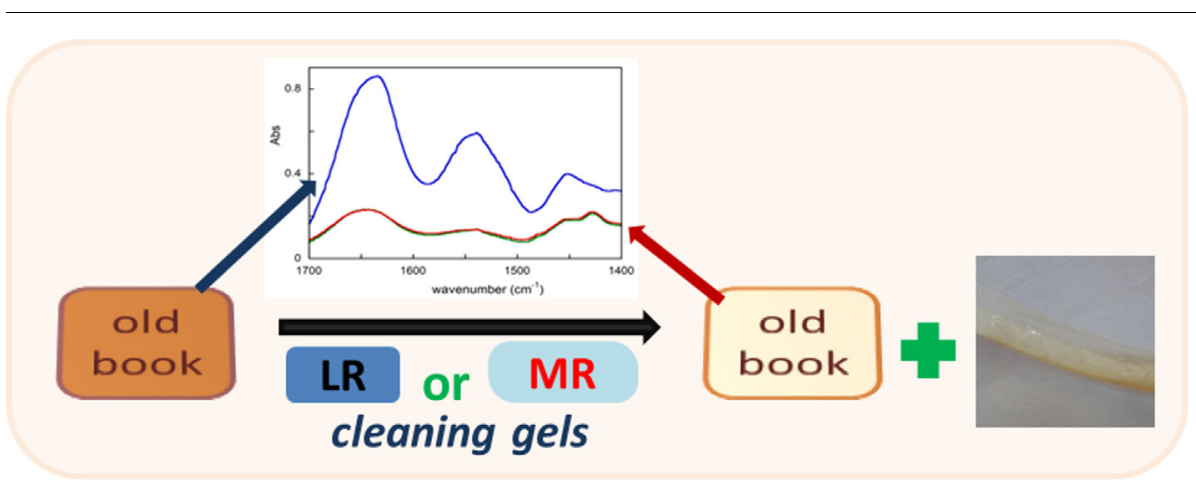

\section{A R T I C L E I N F O}

\section{Article history:}

Received 9 February 2017

Revised 26 April 2017

Accepted 26 April 2017

Available online 29 April 2017

\section{Keywords:}

Semi IPN

Hydrogel

Gellan

Cellulose

Enzymes

Cleaning

Cultural heritage

\begin{abstract}
A B S T R A C T
Hypothesis: Due to their highly retentive properties, innovative recently developed, semi-interpenetrated hydrogels made up of poly(vinyl pyrrolidone) (PVP) chains embedded in a poly(2-hydroxyethyl methacrylate) (p(HEMA)) network should be efficiently used as cleaning material for fragile and degraded paper artworks. In restoration practice, indeed the wet cleaning of these artworks is usually performed by immersion of paper in water, a procedure which may lead to several drawbacks, including paper fibers swelling and dissolution of water-soluble original components.

Experiments: This class of gels were yet presented in literature, but their interactions with paper materials and ability to be spiked with active enzymes (as cleaning agents), have not been analyzed. To establish the suitability of these hydrogels as paper cleaning materials, first, a rheological and microstructural characterization of the gels was performed. Moreover, diffusion of macromolecules inside gels was studied using fluorescence microscopy, to check if these innovative hydrogels can be used as carriers for hydrolytic enzymes. Indeed, pastes and glues are usually found in old paper artworks, and their removal is a very delicate operation that requires a selective action, which is granted by specific hydrolytic enzymes. At the same time, spectroscopic analyses on paper samples under investigation before and after cleaning treatment has been performed, thus assessing the capabilty of these gels as cleaning materials. Findings: With the aim of demonstrating the versatility of these hydrogels, several case studies, i.e., the removal of grime and water-soluble cellulose degradation byproducts, the removal of animal glue and the removal of starch paste from real samples, are presented. Results obtained with these gels have been compared to those obtained by using another gel used for paper artworks cleaning, i.e., Gellan gel.
\end{abstract}

(c) 2017 Elsevier Inc. All rights reserved.

\footnotetext{
* Corresponding author.

E-mail address: antonio.palleschi@uniroma2.it (A. Palleschi).
} 


\section{Introduction}

Wet cleaning is a fundamental operation in paper artworks restoration because it allows the removal of grime, dirt and water-soluble substances arising from cellulose degradation. Wet cleaning also allows for the partial dissolution of aged glues and pastes, even if, for a complete and selective removal, specific hydrolytic enzymes are preferred [1-3].

The traditional cleaning procedure implies the immersion of paper artworks in water $[3,4]$, which eventually induces the removal of sizing agents, i.e., gelatine, the spreading of inks and it also leads to the swelling of cellulose fibers, which may cause the deformation of paper after drying, leading to a significant decrease in the mechanical resistance of the cellulosic network $[2,5-8]$. The usage of hydrogels could overcome the drawbacks induced by this traditional cleaning practice. In fact, when gels are used, the penetration of water into paper is significantly reduced, resulting in minimal damage to the artworks [9-11]. Solvent gels and cellulose derivatives, used as thickening agents for water and solutions, were the first gel-like systems proposed for paper cleaning [12-13]. However, their complete removal from artworks after application is not simple and it often requires mechanical action or the use of solvents, which could be unsafe for the artworks [14]. Recently, physical gels based on natural polysaccharides, such as Gellan gel $(\mathrm{Gg})$, have been proposed for the cleaning of paper artworks. From a rheological point of view, these hydrogels are rigid systems that can be applied and removed from paper in one step, as one body, without leaving residues on the treated surfaces $[2,9,15,16]$. These materials are also biocompatible (in fact they are widely used in food and medicine), and they are thus safe for operators. However, even if the use of Gg represents a great improvement with respect, to water bath, it has some drawbacks. Indeed, its high rigidity renders it unsuitable for non-flat artworks like backs of books, frayed covers or papers containing both glued and unglued parts because it is not able to adhere uniformly and thus the cleaning process could be not homogenous. Furthermore, the biodegradability of these hydrogels imposes their preparation "in situ", shortly before their application and they can be used only once. In this contest, even if the $\mathrm{Gg}$ preparation is very simple, care should be used during the addition (at relatively high temperature) of enzymes [9] to avoid cloths or enzymes denaturation. Moreover, even if the amount of water released by these hydrogels is significantly lower than that used in traditional wet cleaning operations, it is sometimes not sufficiently low to avoid the formation of gores due to the spreading of water on paper samples, thus reducing the possibility of performing a cleaning operation only specific, compromise parts of the artworks.

Finally, highly degraded paper artworks could not usually stand the application of these polysaccharide-based rigid gels. To overcome these drawbacks, making advances in the field of gel for cleaning paper artworks, we have looked for candidates into several materials developed for cultural heritage restoration [17-19]. In particular, a new class of hydrogels proposed for the cleaning of water-sensitive artworks, $[20,21]$ has appeared to be particularly interesting. These hydrogels are based on a semiinterpenetrated network in which chains of poly(vinyl pyrrolidone) (PVP) are embedded in a poly(2-hydroxyethyl methacrylate) $(\mathrm{p}($ HEMA $)$ ) structure. The semi-interpenetrated network takes advantages from both the mechanical stability of the $p$ (HEMA) and the high hydrophilicity of PVP. These hydrogels are highly retentive, soft and transparent and can be easily handled. Furthermore, they are stable, not perishable and can be stored in water for months. p(HEMA)/PVP hydrogels can be used with neat water, or loaded with several polar solvents, such as glycerol and ethanol
[21]. The properties of the hydrogel mainly depend on the $p$ (HEMA)/PVP ratio and on the amount of water used during gel preparation. In fact, changes in gel composition result in hydrogels with different properties (i.e., the hydrophilicity of the network, pore size distribution and the mechanical properties). This means that, in principle, for example, different gels with different hydrophobic properties could be produced, using simply the same protocol, to clean paper samples with different hydrophobic patinas. In this work, two p(HEMA)/PVP hydrogels were used for the removal of unwanted materials from paper artworks and compared to a well-established gel for paper cleaning artworks, i.e., $\mathrm{Gg}$. Indeed, even if these gels have been reported in literature as highly retentive gels usable for cleaning cultural heritage artifacts, their interaction and compatibility with paper materials, as well as their cleaning ability have not been yet characterized. Moreover, old paper artworks often contain pastes and glues, and their removal is a very delicate operation that requires a selective action, which could be granted by specific hydrolytic enzymes. Therefore, in this work the capability of these gels to carry active hydrolytic enzymes as very specific (and biocompatible) cleaning agents has been also studied. The combined use of retentive gel and enzymes, indeed, allows a localized and selective glue removal, thus minimizing time costs and damages on paper materials The suitability of these gels as cleaning agents, has been established performing experiments concerning both the characterization of their microstructural and rheological properties and about water loss, spreading on paper, mobility of molecules into them. To this end, small angle X-ray scattering (SAXS) and field emission scanning electron microscopy (FE-SEM) measurements, creep recovery tests, and the fluorescence recovery after photobleaching (FRAP) experiments have been carried out on gels.

With the aim of demonstrating the versatility of these hydrogels, several case studies are have been carried out and reported, i.e., the removal of grime and water-soluble cellulose degradation by-products, the removal of animal glue and the removal of starch paste from real samples and tuned specimens.

\section{Experimental section}

\subsection{Materials}

$\alpha$-Amylase [EC-232-560-9; 30,500 U/ml], Proteinase $K$ [EC3.4.21.64, $\geq 30 \mathrm{U} / \mathrm{mg}$ ], fluorescein isothiocyanate-dextrans (FITCdextrans) of different molecular weights (average molecular weights: $10 \mathrm{kDa}$ and $40 \mathrm{kDa}$ ), calcium acetate, calcium chloride, 2-Hydroxyethyl methacrylate [HEMA] and poly(vinylpyrrolidone) (PVP) were obtained from Sigma-Aldrich. $\alpha, \alpha^{\prime}$-Azoisobutyronitrile (AIBN) and N,N-methylene-bis(acrylamide) (MBA) and Methylene Blue (MB) were purchased from Fluka. Gellan gum is KELCOGEL CG-LA product by CP Kelco (Atlanta Georgia, USA). New cellulosic paper samples (density $=80 \mathrm{~g} / \mathrm{cm}^{2}$, rate of filtration $=1196 \mathrm{~s} / 100 \mathrm{~mL}$ ) were purchased from ALBET $^{\circledR}$ LabScience. All reagents used were of analytical grade and used without further purification. During all the experiments, ultrapure water obtained from a Millipore system was used.

\subsection{Hydrogels preparation}

Gellan gum-based hydrogel (Gg) was prepared according to a procedure reported elsewhere [9], using commercial deacylated Gellan gum $(20 \mathrm{~g} / \mathrm{L})$ and calcium acetate $(0.4 \mathrm{~g} / \mathrm{L}) . \mathrm{Gg}$ has been stored in refrigerator before use and must be used within few days.

Two semi-IPN hydrogels, based on a polymeric network of $p$ (HEMA) embedding PVP, were prepared. A system is more retentive (MR) while the other one is less prone to retain water (LR). 
This different behavior is due the different ratio between the two polymers, as reported in Table 1 . The preparation procedure of this class of semi-IPN hydrogels is reported elsewhere [20]. These two gels could be stored in water at room temperature for a few months before use.

Some information about the selected gels is reported in Table 1. Water Content (WC) is defined as the ratio between the water in the system and the dry weight of the gel. The swelling ratio of the semi IPNs was obtained from the comparison of gel weight after the synthesis and after about $150 \mathrm{~h}$ of immersion in deionized water.

Enzymes-loaded Gg were prepared by adding an aliquot of an $\alpha$ amylase solution ( $\alpha$-amylase $=24.6 \mu \mathrm{M}$ and $\mathrm{CaCl}_{2}=8 \mathrm{mM}$, $\mathrm{pH}=6.9$ ) or of Proteinase $K$ solution (Proteinase $K=8 \mu \mathrm{M}$ and $\mathrm{CaCl}_{2}=8 \mathrm{mM}, \mathrm{pH}=8$ ) to the Gellan gum and calcium acetate solution, at $55{ }^{\circ} \mathrm{C}$ during cooling in a Petri disk [9]. To load LR ad MR gels, in order to favor enzymes uptake, LR and MR gels have been slightly dehydrated until their weights were reduced by $10-15 \%$. Slightly dehydrated gels were then placed into the $\alpha$-amylase solution ( $\alpha$-amylase $=24.6 \mu \mathrm{M}$ and $\mathrm{CaCl}_{2}=8 \mathrm{mM}, \mathrm{pH}=6.9$ ) or into the Proteinase $K$ solution (Proteinase $K=8 \mu \mathrm{M}$ and $\mathrm{CaCl}_{2}=8 \mathrm{mM}$, $\mathrm{pH}=8$ ) for three hours. Thereafter, gels have been gently surface dried and applied on paper samples.

\subsection{Hydrogel characterization}

\subsubsection{SAXS measurements}

SAXS measurements were carried out with a HECUS S3-MICRO camera (Kratky-type) equipped with a position-sensitive detector (OED $50 \mathrm{M}$ ) containing 1024 channels of width $54 \mu \mathrm{m}$. Cu K $\alpha$ radiation of wavelength $\lambda=1.542 \AA$ was provided by an ultrabrilliant point microfocus X-ray source (GENIX-Fox 3D, Xenocs, Grenoble), operating at a maximum power of $50 \mathrm{~W}(50 \mathrm{kV}$ and $1 \mathrm{~mA})$. The sample-to-detector distance was $269 \mathrm{~mm}$. Measurements were conducted under vacuum to minimize scattering from the air. The Kratky camera was calibrated in the small angle region using silver behenate $(\mathrm{d}=58.38 \AA$ ) [22]. Scattering curves were obtained in the q-range between 0.01 and $0.54 \AA^{-1}$, where $q$ is the scattering vector, $\mathrm{q}=4 \pi / \lambda \sin \theta$, and $2 \theta$ the scattering angle.

Gel samples were placed into a $1 \mathrm{~mm}$ demountable cell having Mylar films as windows. The temperature was set to $25^{\circ} \mathrm{C}$ and was controlled by a Peltier element, with an accuracy of $0.1^{\circ} \mathrm{C}$. All scattering curves were corrected for the empty cell contribution considering the relative transmission factor.

\subsubsection{SEM measurements}

FE-SEM images were collected using a IIGMA (Carl Zeiss Microscopy $\mathrm{GmbH}$, Germany) operating at $2 \mathrm{kV}$ on uncoated samples. All samples were freeze-dried for $24 \mathrm{~h}$ prior the measurements using a BenchTop $2 \mathrm{~K}$ freeze-dryer (VirTis, USA) under 30 mTorr vacuum at $-50{ }^{\circ} \mathrm{C}$.

\subsubsection{Creep recovery and oscillatory measurements}

Creep-recovery and oscillatory measurements were performed using a Discovery HR-3 rheometer from TA Instruments equipped with a parallel-plate geometry of $40 \mathrm{~mm}$ diameter. Measurements were performed at $25^{\circ} \mathrm{C}$ (Peltier temperature control system). During creep-recovery tests a stress of $5 \mathrm{~Pa}$ was applied on the specimen for a duration of $30 \mathrm{~s}$ and the shear strain $\gamma(\mathrm{t})$ was recorded (loading phase). After removal of the stress $\gamma(t)$ was further recorded for $60 \mathrm{~s}$ (recovery phase). The applied stress was chosen within the linear viscoelastic range of all examined hydrogels, which was previously determined by means of amplitude sweep tests (10 Rad/s; strain 10-3-40\%).

Creep component data were interpreted by applying the fourelement model of Maxwell and Kelvin-Voigt (MKV) [23]. According to this model the overall deformation of the sample, $\varepsilon(\mathrm{f})$, is given by:

$\varepsilon(f)=\left(\sigma_{0} / \mathrm{E}_{\mathrm{E}}\right)+\left(\sigma_{0} / \mathrm{E}_{\mathrm{VE}}\right)\left(1-e^{-t /\left(\eta_{\mathrm{VE}} / \mathrm{E}_{\mathrm{VE}}\right)}\right)+\left(\sigma_{0} / \eta_{\mathrm{V}}\right) \mathrm{t}$

were $E_{\mathrm{E}}$ and $\mathrm{E}_{\mathrm{VE}}$ are the moduli of the elastic components (in the pure elastic region and in the viscoelastic region), corresponding to springs in the Kelvin Voigt model, while the dashpots represent the viscosity, in the viscoelastic region and in the viscous region $\left(\eta_{\mathrm{VE}}, \eta_{\mathrm{V}}\right)$.

\subsubsection{Hydrogel water release analysis}

The amount of water released by the gels was obtained by measuring changes in weight of new cellulosic paper samples onto which gels were placed. Data are given in percentage, where $100 \%$ is the amount of water uploaded by paper immersed in a bath, to mimic a traditional cleaning procedure.

\subsubsection{Enzymes uptake and diffusion of macromolecules in hydrogels, investigations}

The diffusion of macromolecules inside hydrogels was investigated by means of fluorescence recovery after photobleaching (FRAP). Experiments were performed on hydrogels loaded with different fluorescein isothiocyanate (FITC) labeled dextrans of $10 \mathrm{kDa}$ and $40 \mathrm{kDa}$ [24]. Such dextrans were used as models of macromolecules having different dimensions. To load hydrogels, dextran solutions at $1.5 \mathrm{~g} / \mathrm{L}$ have been used. Before loading, $\mathrm{p}$ (HEMA)/PVP gels have been slightly dehydrated until their weights were reduced by $10-15 \%$. To load $\mathrm{p}$ (HEMA)/PVP gels with the desired macromolecules, they were immersed in the dye solutions for three hours at room temperature. On the other hand, dextrans loaded Gg gels were prepared by adding an aliquot of the dye solution to the Gg before cooling [9]. FRAP experiments were performed on a Olympus Fluoroview 1000 Confocal Laser Scanning System equipped with an inverted microscope, Olympus IX-81. Experiments were carried out using a $60 \times / 1.35$ oil immersion objective. Bleaching experiments were performed using the $488 \mathrm{~nm}$ line of a $30 \mathrm{~mW}$ argon ion laser at its maximum intensity. Twenty pre-bleach images (resolution: $128 \times 128$ pixels) at $13 \%$ of maximum laser intensity were collected; thereafter, a uniform region of interest (ROI), having a $20 \mu \mathrm{m}$ diameter, was bleached for $2 \mathrm{~s}$. After bleaching, 500 images were collected at intensity lower than $13 \%$ in order to follow the fluorescence recovery inside the bleached ROI. The time interval between consecutive images was set to $0.2 \mathrm{~s}$. Diffusion coefficients of dextrans were obtained from the experimental curves by using the equation $\mathrm{D}=\left(\mathrm{w}^{2} /\left(4 \tau_{1 / 2}\right) \gamma_{\mathrm{D}}\right.$, where $\mathrm{w}$ is the radius of the bleached spot,

Table 1

Composition, water content (WC) and swelling ratio of the three selected hydrogels.

\begin{tabular}{|c|c|c|c|c|}
\hline Hydrogels & HEMA (\%) & Gellan (\%) & WC (\%) & Swelling ratio (\%wt) \\
\hline $\mathrm{Gg}$ & - & 2 & 98 & n.d. ${ }^{a}$ \\
\hline MR & 25 & - & 76 & 250 \\
\hline LR & 10 & - & 86 & 700 \\
\hline
\end{tabular}

a The preparation procedure of Gg does not require the immersion in water after preparation since Gg is applied as it is after gelation. 
$\tau_{1 / 2}$ is the recovery time of half of the original intensity and $\gamma_{D}$ is a constant whose value is 0.88 for circular beam $[25,26]$. Details about the diffusion of material from the paper to gel have been obtained by performing optical microscope experiments (Celestron, Microcapture Pro, Celestron, Torrance, USA) on paper loaded with MB [27] during cleaning with LR or MR gels.

\subsubsection{UV-Vis absorption experiments}

UV-Vis absorption experiments on LR and MR gels loaded with the fluorescent FITC- $\alpha$-amylase were carried out on a Cary-100 spectrometer (Agilent, Santa Clara, CA USA) using a suitable home-made holder. To load p(HEMA)/PVP gels with FITC-labeled$\alpha$-amylase, they were previously slightly dehydrated until their weights were reduced by $10-15 \%$ and successively immersed in the macromolecule solutions for three hours at room temperature. The concentration of FITC-labeled- $\alpha$-amylase solution was $126 \mu \mathrm{M}$. FITC-labeled- $\alpha$-amylase was prepared according to a procedure reported elsewhere [28].

\subsection{Cleaning tests on paper}

The three selected hydrogels were tested on real paper samples for the removal of water-soluble compounds, animal glue and starch paste. Water-soluble compounds, including grime and byproducts of cellulose degradation, were removed from the "Breviarium Romanum ad usum Fratrum Minorum", a breviary of the 18th century, made of rag pulp [6]. The gels were also used for the removal of animal glue from the cover of the same breviary. On the other hand, starch paste was removed by gels from several paper fragments belonging to a 20th century book (E. Antonini, Guida alle esercitazioni di chimica biologica, Ed. Universo, 1966).

For the removal of grime and water-soluble compounds, gels were used as prepared, swollen in water. The removal of animal glue and starch paste was carried out by means of gels loaded with enzymes. To perform cleaning experiment on yet used MR gels, gels used to clean paper samples loaded with a MB solution, were swollen in distilled water for two days, changing water periodically, until in the UV-Vis spectrum of the gel, bands due to MB disappear.

Applicative tests of gels on paper were performed with the following procedure: paper samples were fully covered with the gel; over the gels a PET film (Mylar), uniformly pressed to ensure a close contact between the gel and the sample, was applied, with the aim of reducing water evaporation. In the case of LR and MR application, after $30 \mathrm{~min}$, the gel was turned, and after $60 \mathrm{~min}$ the gel was changed. After the cleaning with enzyme-loaded gels, a subsequent $1 \mathrm{~h}$ of cleaning with a no enzymatic gel was performed.

\subsubsection{Paper samples characterization: FTIR, colorimetric and $\mathrm{pH}$ analyses}

Cleaning efficacy was checked using FTIR, colorimetric and $\mathrm{pH}$ measurements. FTIR spectra of paper samples were acquired on a Thermo-Scientific (mod. Is50) instrument (Thermo Scientific Inc., Madison WI), equipped with an attenuated total reflectance (ATR) Diamond cell for measurement in the $4000-525 \mathrm{~cm}^{-1}$ region, at a resolution of $2 \mathrm{~cm}^{-1}$. A total of 32 scans were collected for each sample. Also in this case, spectra were collected by placing the paper samples directly on the ATR cell. The presence of cellulosic degradation products on paper samples was determined by performing a deconvolution of bands in the $1400-1900 \mathrm{~cm}^{-1}$ region of the FTIR spectra. A sum of Lorentzian/Gaussian functions has been used for deconvolution on normalized absorbance spectra by using OMNIC software $[2,6]$.

Colorimetric measurements were performed by using a Konica Minolta CR-200. Filter paper (DP 593 125) from ALBET LabScience was used as a reference. Colorimetric coordinates in the CIELab colorspace ( $\left.\mathrm{L}, \mathrm{a}^{*}, \mathrm{~b}^{*}\right)$, using a D65 illuminant and a $10^{\circ}$ observer, were obtained. Color differences before and after cleaning tests are reported in terms of $\Delta \mathrm{E}$, which is the distance between two points in the color space. Results are obtained from three measurements on the same spot.

Measurements of $\mathrm{pH}$ were carried out on the paper surface [29] by using an Amel Instrument 334-B pHmeter with a combined glass electrode $\mathrm{Ag} / \mathrm{AgCl}$ and a porous PTFE diaphragm (Crison Instruments, Spain); RSD was $5 \%$, calculated on three measurements of the same sample.

\subsubsection{Hydrogel characterization after cleaning: HPLC analysis}

HPLC analyses were performed with a THERMOQUEST instrument (Shimadzu, Kyoto, Japan), equipped with two pumps and an UV/Vis detector LCGA SPD-10A (Shimadzu, Kyoto, Japan). The apparatus was equipped with a controller SN 4000 (Shimadzu, Kyoto, Japan) that can process data in real time through the CHROMQUEST software. The chromatographic analysis was performed on extracts obtained by treating $1 \mathrm{~cm}^{2}$ of every gel sample with $1 \mathrm{~mL}$ of distilled water stirring on the rotating wheel (Dynal AS, Sweden) overnight at room temperature. The analyses were carried out in isocratic condition using $25 \mathrm{mM}$ phosphate buffer at $\mathrm{pH} 2.4$ and $1 \%(\mathrm{v} / \mathrm{v})$ methanol as a mobile phase. The flow rate was $0.7 \mathrm{~mL} / \mathrm{min}$, and using a detection wavelength equal to $\lambda=210 \mathrm{~nm}$. Prior use all mobile phase were degassed daily with ultrasonic bath and vacuum $[2,6]$.

Each chromatographic analysis was repeated three times in the same day (reproducibility intra-day RSD\%=2\%) and on different days (reproducibility inter-day RSD\% = 2\%) for all the samples. Also the measurements were carried out three times on the same sample extract $(\mathrm{RSD} \%=2 \%)$ and on three different extractions of the same paper sample $(\mathrm{RSD} \%=4 \%)$. The attention was focused on ascorbic, malic, lactic, oxalic, citric, and succinic acids, all cellulosic degradation byproducts $[2,6]$.

\section{Results and discussion}

\subsection{Hydrogels characterization: SAXS, oscillatory and creep recovery experiments}

SAXS investigations were carried out to obtain information about the structure of the selected hydrogels. SAXS curves of hydrogels could be fitted using a model proposed by Hammouda and widely used [30,31-33]. This model, used to fit both, neutral and charged polymeric solutions, uses in its original form a first low-q clustering term and a second high-q solvation contribution:

$\mathrm{I}(q)=\mathrm{A} / \mathrm{q}^{\mathrm{n}}+\left[\mathrm{C} / 1+(\mathrm{q} \xi)^{\mathrm{m}}\right]+\mathrm{B}$

The first term describes the Porod scattering from cluster, while the second term is a generalized form of a Lorenzian function used to describe the scattering from polymer chains. A and $\mathrm{C}$ are $q$ independent constants, $\mathrm{B}$ is background contribution, $\xi$ is the correlation length, while $\mathrm{n}$ and $\mathrm{m}$ are clustering and solvation Porod exponents, respectively.

Since in the acquired SAXS profiles no intensity increase was observed in the low-q region (Fig. 1), the low-q clustering term was omitted and the SAXS curves were modeled taking into account only the solvation term and the flat background, according to a simplified Correlation Length Model [34]:

$\mathrm{I}(q)=\left[\mathrm{C} / 1+(\mathrm{q} \xi)^{\mathrm{m}}\right]+\mathrm{B}$

where $\mathrm{C}$ and $\mathrm{B}$ are $q$-independent constants, $\xi$ is the correlation length and $\mathrm{m}$ is the Porod exponent. The precise meaning of the correlation length $\xi$ depends on the system microstructure; however, it 


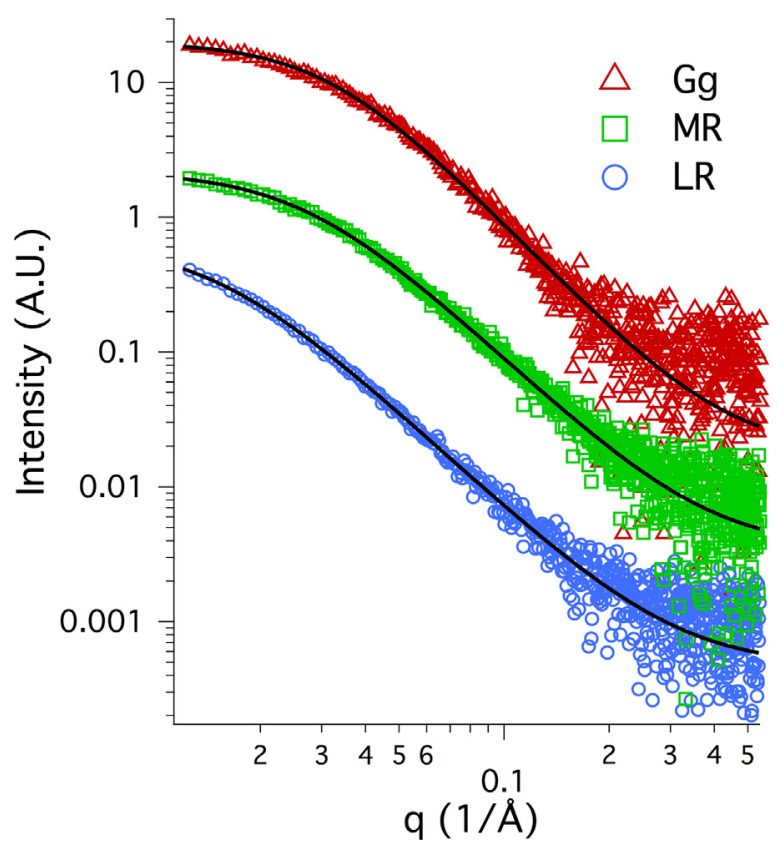

Fig. 1. SAXS intensity distribution in a log-log scale for the three hydrogels (circles for LR, squares for MR, and triangles for Gg). Solid lines are obtained by fitting the data with the Correlation Length Model. Curves are shifted upward by an arbitrary factor to avoid overlap.

can be generally regarded as an estimate of the average entanglement distance [33]. $\xi$ is large in the case of highly correlated systems, such as polymers and gels. On the other hand, Porod exponent vary from 1 , for $1 \mathrm{D}$ object such as a rod, to 4 for object with smooth surface. A Porod exponent in the range 3-4 characterizes rough interfaces of fractal dimension $D$ with $n=6$-D. A Porod exponent between 2 and 3 is for "mass fractals" such as branched systems, i.e., gels, or networks [35]. In Table 2, the parameters obtained from the fitting of the SAXS curves using the Correlation Length Model are reported. Solid lines in Fig. 1 are the curves obtained from fitting.

In all the three selected systems, the Porod exponent $\mathrm{m}$ obtained from the fitting of SAXS curves is in the range 2-3, which correspond to branched systems, such as hydrogels. The $m$ value can be also related to the Flory excluded volume exponent $\mathrm{v}$ $(\mathrm{m}=1 / \mathrm{v})$ that describes the interactions between polymer chains and the solvent in which they are immersed. In particular, for fully swollen polymer chain $\mathrm{v}$ is $3 / 5(\mathrm{~m}=1.66)$, while a $\mathrm{v}$ of $1 / 2(\mathrm{~m}=2)$ is observed when polymer is in a theta solvent, i.e., when interactions between chain-chain and chain-solvent molecules are equivalent. On the other hand, $v$ is $1 / 3(\mathrm{~m}=3)$ if chain-chain interactions are favored, leading to the so-called "chain collapse" [34]. In all the investigated systems, polymer attractive interactions seem to be favored, even if in $\mathrm{p}$ (HEMA)/PVP hydrogels, the polymer is closer to the theta condition with respect to $\mathrm{Gg}$.

Gelation in Gellan gum-based systems occurs through cooling of an aqueous solution. The first step in gelation is due to the conversion of the polymer from a disordered coil state to a double helix form. As long as the double helices are not associated, a gel network cannot be obtained. When the gel point is reached, double helices associate themselves into stable aggregates, leading to the formation of a true gel. In particular, it has been showed that the mesh size of the Gellan gum network increases during sol-gel transition [36]. Aggregation is inhibited by electrostatic repulsions between the helices. Therefore, the addition of monovalent and bivalent cations to the Gellan solution favors the aggregation of double helices [37].

In literature, several studies on the strand dimension in pure gellan systems networks and in presence of monovalent cations have been conducted by SAXS [38-40]. As expected, the increase in the number of double helices per strand increases the size of the strands. Moreover, the addition of monovalent ions to the system increases the mass fraction of the more aggregated population. The dimension of strands ranges between $0.30 \mathrm{~nm}$ to $1.37 \mathrm{~nm}$. In our study, the fitting of Gg hydrogel SAXS curves with the Correlation Length Model here proposed, yields a $\xi$ of $31.7 \AA$ (Table 2). This is in accordance to the fact that the presence of divalent cations leads to the formation of longer and thicker strands [41].

In $\mathrm{p}$ (HEMA)/PVP hydrogels, the correlation length increases as a function of the decrease of polymer fraction in the systems. In fact, the $\xi$ value of MR that has the highest polymer content, $h$ is almost half the one of LR hydrogel. According to literature, the mesh size increases with the increase in the swelling ratio [42]. As a matter of fact, MR has a swelling ratio that is about 3 times lower than the swelling ratio of LR. The values are reported in Table 1. Rheological measurements provide information about the behavior of a material when a stress is applied, and are therefore pivotal in choosing the right formulation for specific applications. In a paper cleaning process, the gel must be handled, that is applied and removed as one body. In addition, it must bear a slight pressure (about $30 \mathrm{~Pa})[2,6,9,10]$, for almost an hour, to ensure the close contact between the gel and the paper without inducing gel brittleness, strong deformation and fragmentation.

During an amplitude sweep test, the frequency of the deformation is kept constant, while the amplitude of the deformation is increased. As can be seen in Fig. 2, both the storage and the loss moduli, $G^{\prime}$ and $G^{\prime \prime}$ respectively, are constant in all the three systems in a quite large range of applied deformations. This region is called linear viscoelastic region. Moreover, the storage modulus G' is several times higher than the loss modulus G" in all the investigated systems, indicating that all the systems have a solid-like behavior. As soon as the moduli start to decrease, i.e., at the end of the linear viscoelastic region, the structure of the material is disturbed by the deformation. From literature [9], it can be seen that Gg is more rigid of both the semi-IPNs gels, being its G' about $18 \mathrm{kPa}$. Moreover, the range in which $\mathrm{Gg}$ exhibits a linear viscoelastic behavior is wider, and ranges from $0.1 \mathrm{~Pa}$ to $470 \mathrm{~Pa}$. Among the two pHEMA/ PVP systems, LR is more flexible than MR, being both $G^{\prime}$ e $G^{\prime \prime}$ significantly lower ( $5 \mathrm{kPa}$ and $0.3 \mathrm{~Pa}$ for LR and $11 \mathrm{kPa}$ and $0.7 \mathrm{~Pa}$ for MR).

The creep-recovery tests were conducted within the linear viscoelastic region, i.e., with an initial stress of $5 \mathrm{~Pa}$. As can be seen in Fig. 3, the three hydrogels show a deformation typical of viscoelastic solids. During the load phase, a constant stress is applied. As a result of this stress, the strain in gels increases steadily, displaying

Table 2

Parameters obtained from the fitting of the SAXS curves of the investigated hydrogels.

\begin{tabular}{|c|c|c|c|c|}
\hline Hydrogel & $\mathrm{C}$ & $\xi(\AA)$ & $\mathrm{m}$ & B \\
\hline $\mathrm{Gg}$ & $10.8 \pm 0.1$ & $31.7 \pm 0.3$ & $2.68 \pm 0.02$ & $0.010 \pm 0.002$ \\
\hline MR & $21.4 \pm 0.2$ & $36.8 \pm 0.3$ & $2.45 \pm 0.01$ & $0.034 \pm 0.002$ \\
\hline LR & $43.2 \pm 0.7$ & $66.6 \pm 0.8$ & $2.40 \pm 0.01$ & $0.031 \pm 0.002$ \\
\hline
\end{tabular}




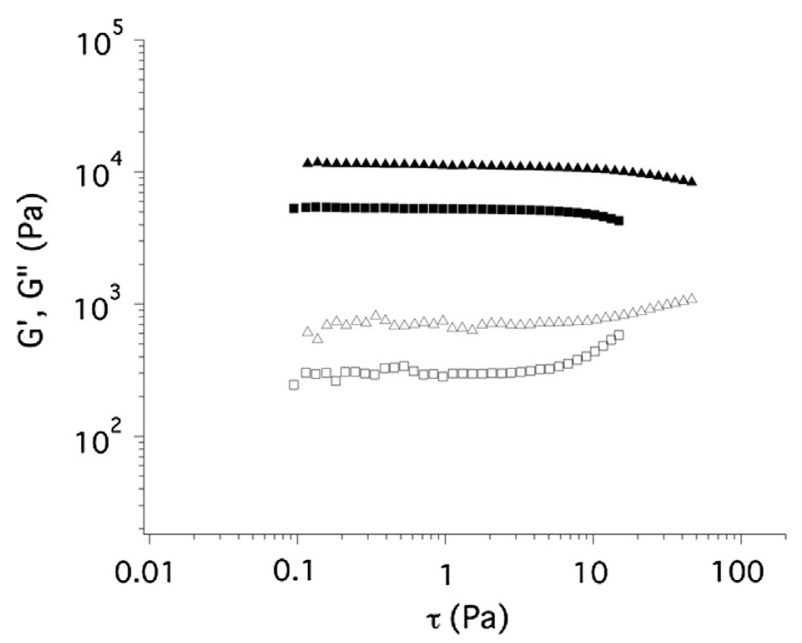

Fig. 2. Curves obtained from amplitude sweep tests of the three selected hydrogels (triangles for MR and squares for LR semi-interpenetrated pHEMA/PVP formulations). $G^{\prime}$ is the storage modulus, while $G^{\prime \prime}$ is the loss modulus.

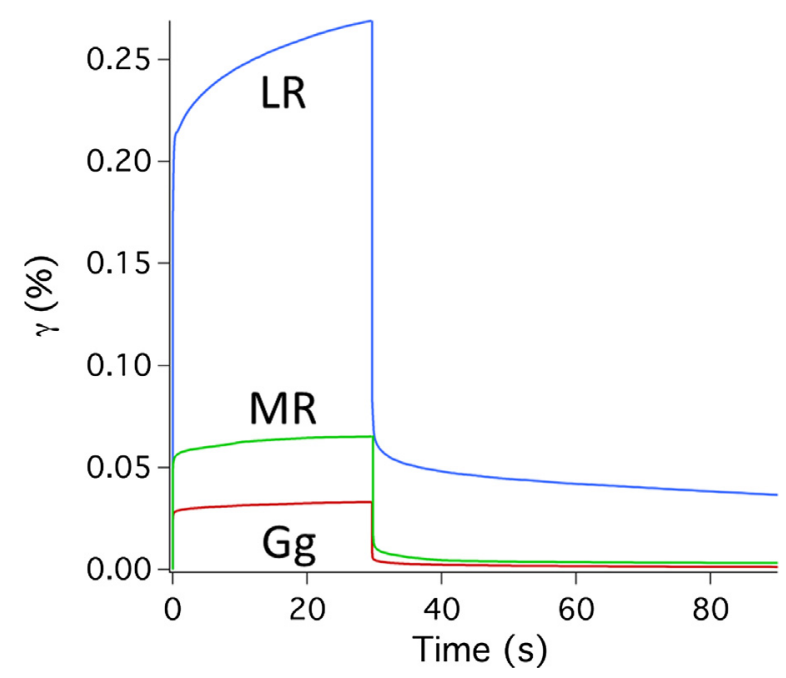

Fig. 3. Creep-recovery curves of the three selected hydrogels. The different behavior of LR (blue) with respect to MR (green) and Gg (red) is evident. (For interpretation of the references to colour in this figure legend, the reader is referred to the web version of this article.)

a curved time-dependent trend. Once the stress is removed, systems relax, and the strain is almost completely recovered.

Among the tested systems, LR displays the highest response to the applied stress. After the recovery phase, the strain is only partially recovered, resulting in a higher permanent deformation (D\%, Table 3). This suggests a predominant viscous behavior in LR with respect to the other formulations that show a permanent deformation of about $4 \%$.

In Table 3, the parameters obtained from the fitting of the load phase curves using the Maxwell and Kelvin-Voigt model (MKV) are reported. $\mathrm{Gg}$ is the most elastic system, being its elastic constant of pure elastic response $\left(E_{E}\right)$ about 2 times higher than MR and 9 times higher than LR. The second term of the fitting function describes the viscoelastic response of the hydrogels. $\mathrm{Gg}$ is the stiffest hydrogel, displaying the highest values of the elastic constant in the viscoelastic region $\left(\mathrm{E}_{\mathrm{VE}}\right)$ and of the viscosity in the same range $\left(\eta_{\mathrm{VE}}\right)$, as expected for a material that had better withstand deformation [43].

As reported in Table 3, $E_{E}$ of MR is higher than $E_{E}$ of $L R$. The elastic constant in the pure elastic region is related to the crosslinking density of a system. In fact, MR contains a higher amount of polymer and its degree of swelling is lower than LR, resulting in a more crosslinked network.

The Voigt viscosity, $\eta_{v}$, is related to internal friction of polymer chains. Higher values of $\eta_{V}$ are typical of a system in which slippage and stretch of polymer chains in response to an applied stress are hampered [44]. The $\eta_{V}$ of MR is $3.4 \mathrm{kPa}$, four times higher than LR. Accordingly, MR shows significantly less permanent deformation due to the scarce mobility of the polymer chains within its network.

In conclusion, the rheological characterization of the three formulations shows that these hydrogels are rigid systems that can be applied and removed from paper in one step, as one body, without leaving residues on the treated surfaces. Moreover, these data indicate that LR and MR con be bent in order to adhere also on non-flat artworks; this is not the case for Gg due to its high rigidity (Fig. 4). In Fig. 5, pictures taken on xerogels (lyophilized systems) are reported. In all the three hydrogels, can be seen a sponge-like micron-sized porous structure. The different chemical nature of the gels is clearly evident from these pictures. Gg shows an aligned filamentous network in which large pores and a thin web structure, having smaller size, coexist. The larger pores have a diameter that ranges from 2 to $5 \mu \mathrm{m}$, while smaller pores are submicron sized. Semi IPNs display a not oriented porous structure, and a more uniform pores size distribution. In particular, MR shows a more regular and compact structure, in which most of the pores seems to be not open. On the other side, LR, which has lower polymer content, displays thinner and more flexible pores walls. A more compact microstructure, as the one displayed by MR, results in a stiffer system, as confirmed by the difference in rheological behavior between the two semi IPNs systems (Table 3).

Differences in hydrogel microstructures shown by SEM images (Fig. 5) are confirmed by water uptake data, reported in Fig. 6. After two hours of application, paper weight increment due to water released from $\mathrm{p}$ (HEMA)/PVP gels are $34 \%$ and $31 \%$ for LR and MR, respectively. On the other hand, water uptake of paper due to $\mathrm{Gg}$ is significantly higher (50\%), even after $30 \mathrm{~min}$ of application. This means that LR and MR are highly retentive systems, whose application could hamper the eventual degradation of paper due to the swelling of fibers/loss of cellulose crystallinity that could occur during the process and the leaching of water-sensitive components (i.e., sizing, inks, dyes, etc). This property leads to a great advantage in the paper cleaning restoration that is the possibility of using these gels for a much localized action on the artworks. As shown in the Fig. S1, the action of LR and MR on new paper samples soaked with a solution of MB, leads to the loss of the intensity of the color only in the treatment zone, with no or very little

Table 3

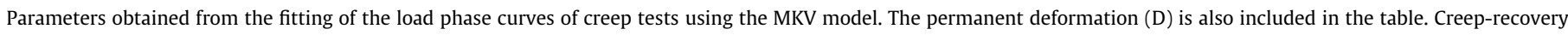
tests were performed at a constant stress of $5 \mathrm{~Pa}\left(\sigma_{0}\right)$.

\begin{tabular}{|c|c|c|c|c|c|}
\hline Hydrogel & $\mathrm{E}_{\mathrm{E}}(\mathrm{kPa})$ & $\eta_{\mathrm{v}}(\mathrm{kPa} \cdot \mathrm{s})$ & $\mathrm{E}_{\mathrm{VE}}(\mathrm{kPa})$ & $\eta_{\mathrm{VE}}(\mathrm{kPa} \cdot \mathrm{s})$ & $\mathrm{D}(\%)$ \\
\hline $\mathrm{Gg}$ & 0.18 & 54 & 2.4 & 8.1 & 3.9 \\
\hline MR & 0.09 & 30 & 0.9 & 3.4 & 4.1 \\
\hline LR & 0.02 & 5 & 0.2 & 0.8 & 13.7 \\
\hline
\end{tabular}



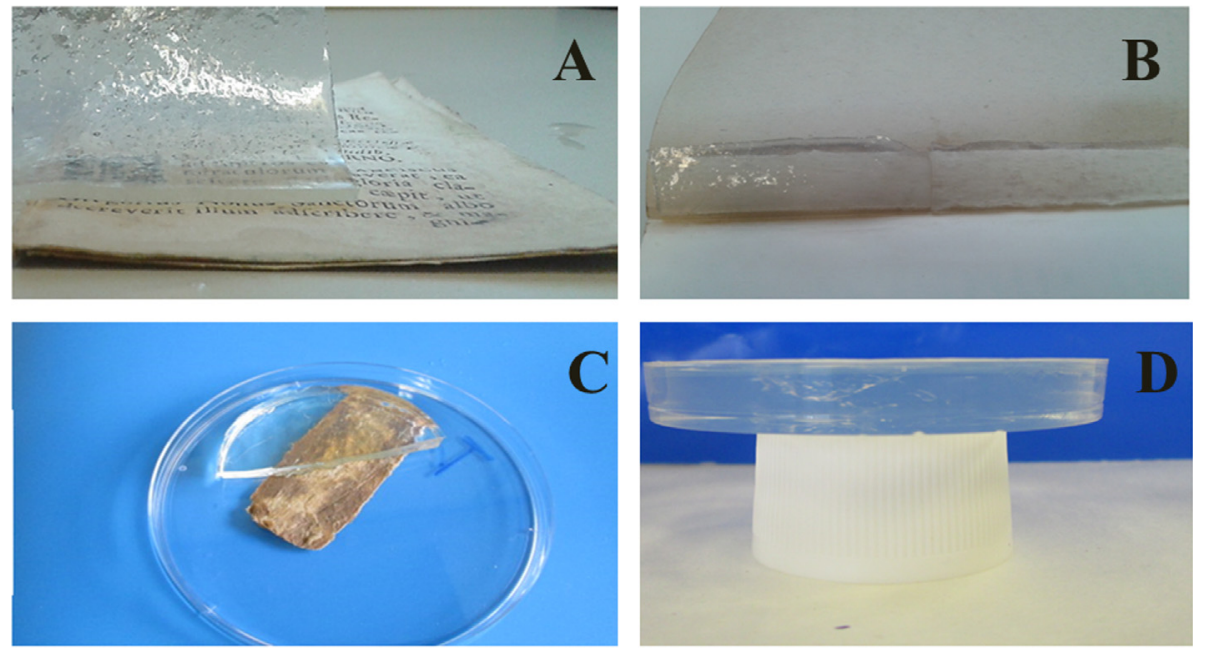

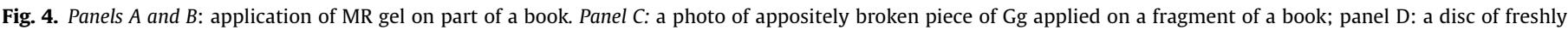
prepared Gg. These photos attest the different rigidity of the gels.
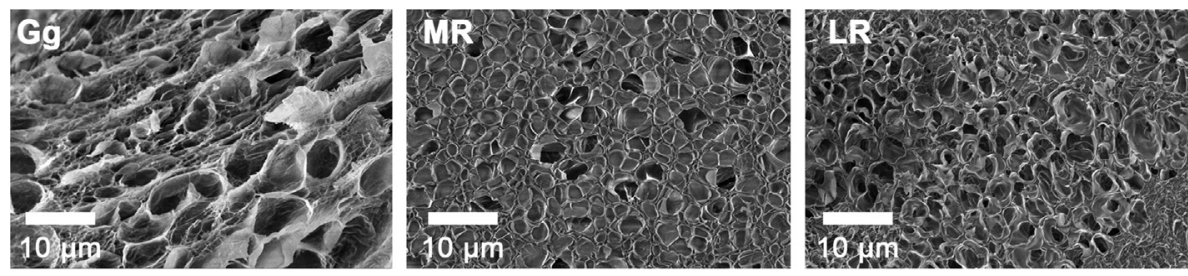

Fig. 5. SEM pictures of the three selected hydrogels (magnification $5 \mathrm{~K}$ ).

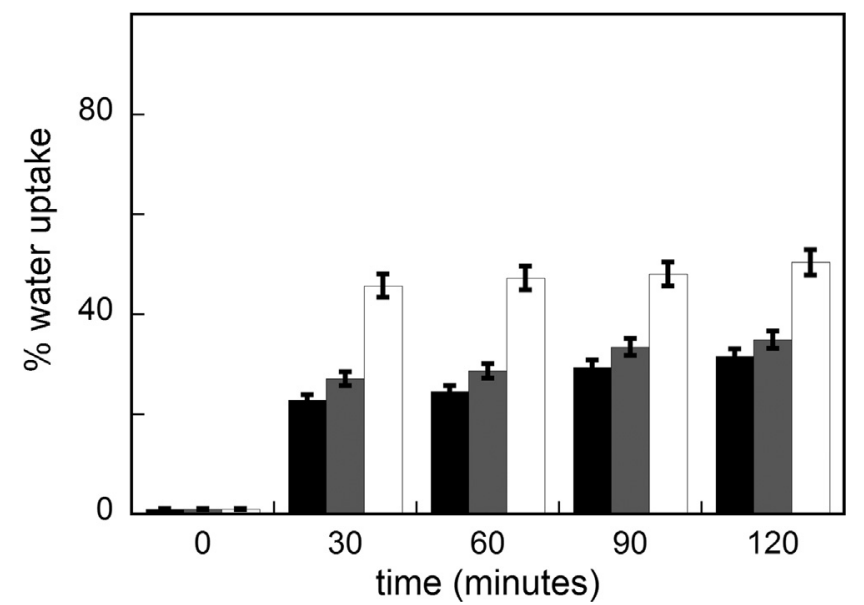

Fig. 6. Water uptake of paper samples treated for $30^{\prime}, 60^{\prime}, 90$ and $120^{\prime}$ with MR gel, (black), LR gel (gray) or Gg gel (white). Data are given in percentage with respect to water uptake by paper immersed in water.

spreading of the dye in adjacent areas of the samples. This is not the case when $\mathrm{Gg}$ is used.

\subsection{Enzymes uptake and diffusion of macromolecules in hydrogels}

Pastes and glues are usually found in old paper artworks, and their removal is a very delicate operation that requires a selective action, which could be granted by hydrolytic enzymes. In this regards our hydrogels were tested to evaluate their ability to load macromolecules. In particular, enzymes should remain active once inside the gel in order to digest the glue during the cleaning process; moreover, the gel should adsorb and entrap the hydrolysis products. To this end, experiments concerning protein uptake, translational mobility and activity of the enzymes into the gel as a function of time were performed. To evaluate the protein contents in gels, UV-Vis absorption experiments on gels loaded with the fluorescent FITC- $\alpha$-amylase were performed. It is worth noting that the hydrodynamic radius, $\mathrm{RH}$, of $\alpha$-amylase is higher than the radius of Proteinase $\mathrm{K}\left(\mathrm{RH}_{\alpha \text {-amylase }}=3.2 \mathrm{~nm}\right.$ [45]; $\mathrm{RH}_{\text {Proteinase } K}=$ $2.4 \mathrm{~nm}$ [46]), and therefore FITC- $\alpha$-amylase was considered representative of both proteins. In Fig. 6, UV-Vis spectra are reported. The absorbance value in graph correspond to enzyme concentrations of $30 \pm 5 \mu \mathrm{M}$ in LR and $18 \pm 3 \mu \mathrm{M}$ in $\mathrm{MR}$, indicating

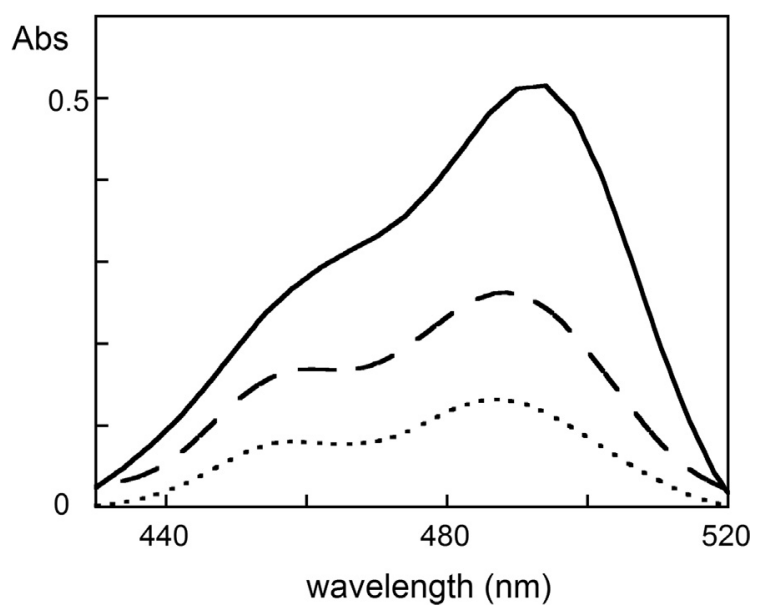

Fig. 7. Absorption spectra of FITC-amylase in solution (continuous line), in LR gel (straight line), and in MR gel (dotted line). 
that after three hours, loading percentages are $25 \pm 4 \%$ and $13 \pm 2 \%$ for LR and MR, respectively. For comparison, in Fig. 7, the absorbance of the FITC- $\alpha$-amylase solution is also reported.

Fluorescence Recovery After Photobleaching (FRAP) experiments have been used to evaluate the translational mobility of molecules into hydrogels. To determine the molecular diffusion in hydrogels, FITC-labeled dextrans, with $10 \mathrm{kDa}$ and $40 \mathrm{kDa}$ molecular weight, have been used as model compounds because their hydrodynamic radii, $\mathrm{RH}$, are close to those of the two enzymes $\left(\mathrm{RH}_{40 \mathrm{kDa}}=4.8 \mathrm{~nm} ; \mathrm{RH}_{10 \mathrm{kDa}}=2.0 \mathrm{~nm}\right)$ [9]. As can be seen in Fig. 8 and Table 4, the diffusion of dextrans in gels is lower than in solution, indicating that the mobility of macromolecules in hydrogels is restricted, probably due to the hindrance of polymeric chains on probes $[47,48]$. It should be noted that the diffusion coefficients and the relative mobile fractions (k) obtained for LR and MR gels are lower than those of $\mathrm{Gg}$, thus suggesting that enzyme mobility is more restricted in the two chemical gels; nevertheless, these measurements show that a fraction of macromolecules is able to diffuse in the gels, making them suitable as carrier for enzymes acting as cleaning agents on paper samples. These results are in good accordance with what shown by SEM images and water uptake measurements (Figs. 5 and 6, respectively).

\subsection{Hydrogel application on paper samples}

In the first place, hydrogels in pure water were applied on several pages of the Breviarium Romanum ad usum Fratrum Minorum, a breviary of the 18th century, made of rag pulp, with the aim of removing cellulose degradation byproducts and grime. In Fig. 9a, FTIR-ATR spectra of paper samples before and after cleaning tests are reported. The spectra show the typical pattern of cellulose characterized by absorption bands in the region $1500-950 \mathrm{~cm}^{-1}$ due, for instance, to $\mathrm{CO}$ and $\mathrm{CC}$ stretching, $\mathrm{CCH}$ and $\mathrm{OCH}$ deformation, $\mathrm{COH}$ and $\mathrm{HCH}$ bending [51,52]. As shown in Fig. 9a, the spectra obtained before and after the cleaning process are comparable; indeed, after gel application, the characteristic peaks [20] of $\mathrm{p}$ (HEMA) $\left(1724 \mathrm{~cm}^{-1}\right)$ and PVP $\left(1654 \mathrm{~cm}^{-1}\right)$ are not visible, indicating that no detectable gel residues are left on the surface after treatment with LR and MR hydrogels (Fig. S2). To determine the efficacy of the proposed cleaning hydrogels for the removal of cellulose degradation products, deconvolution of FTIR spectra into the characteristic bands attributed to several compounds that are usually found on degraded paper has been performed [2,6,53]. Peak deconvolution allows estimating the oxidation state of cellulose, which is expressed by the oxidation index (OI) [53]. The OI is given by the ratio between the integrals of two IR regions, localized respectively at $1664-1837 \mathrm{~cm}^{-1}$ and $1500-1664 \mathrm{~cm}^{-1}$ (avoiding the band due to bound water, which maximum is at $1639 \mathrm{~cm}^{-1}$ ). This definition stems from the fact that bands attributed to carboxyl and carbonyl groups, which are formed at the final degradation stages of cellulose, are localized at higher wavenumbers

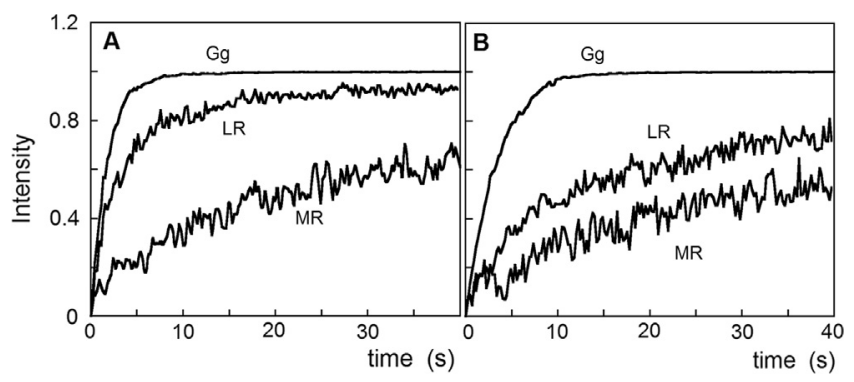

Fig. 8. FRAP curves obtained using $10 \mathrm{kDa}$ FITC-dextran (panel A) and $40 \mathrm{kDa}$ FITCdextran (panel B) in Gg, LR,and MR hydrogels.
(1745-1710 $\mathrm{cm}^{-1}$ ) with respect of bands due to the presence of oxidation intermediates of cellulose $\left(1660-1620 \mathrm{~cm}^{-1}\right)$. Thus, high OI values indicate more degraded paper artworks. The OI of the sample before cleaning test is 0.40 . A significant decrease of OI was observed after application of the tested hydrogels, which decreases to, $0.06 \pm 0.01,0.05 \pm 0.01$ and $0.04 \pm 0.01$, for MR, $L R$, and $\mathrm{Gg}$ respectively. Such results clearly indicate that all hydrogels are able to remove cellulose oxidation/hydrolysis byproducts from real paper samples, being LR and Gg slightly more effective than MR. The FTIR results were confirmed by the increase of $\mathrm{pH}$ values obtained after the cleaning tests (from 7. $1 \pm 0.1$ to $7.7 \pm 0.2$, $7.9 \pm 0.1$ and $8.3 \pm 0.2$ for samples cleaned with, LR, MR, and Gg, respectively). These data, indeed demonstrate that acidic components, involved in degradation processes, are removed $[1,54]$. Interestingly, a preliminary proof was performed using a re-used MR gel. Using this gel, the obtained OI index was $0.07 \pm 0.01$, thus suggesting that these gels could be reusable. Pictures taken on paper samples confirmed the cleaning ability of the gels (Fig. S3). In fact, treated papers appear cleaner and brighter than untreated one, because hydrogels removed the patinas and oxidation products that are responsible for paper browning. HPLC analysis (Table 5), performed on gels samples before and after cleaning process, indicates that LR and MR gels are able to remove acidic cellulosic by-products in different extent from Gg, LR being a little more able than MR. Interestingly, the two gels under study have different affinity for acids with respect to $\mathrm{Gg}$. For assessing the cleaning efficiency of the selected hydrogels, tests for the removal of animal glue were carried out on the cover of the "Breviarium Romanum ad usum Fratum Minorum". Prior to application, the gels were loaded with Proteinase $K$, according to the procedure indicated in the "Materials and Methods" section. Fig. 9b shows the spectra of paper samples before and after cleaning. In these spectra the bands related to the presence of animal glue [55,56], Amide I (1600$1700 \mathrm{~cm}^{-1}, \mathrm{C}=\mathrm{O}$ stretching) and Amide II $\left(1500-1600 \mathrm{~cm}^{-1}, \mathrm{C}-\mathrm{N}\right.$ stretching in combination with $\mathrm{N}-\mathrm{H}$ bending), as well as the bands of cellulose (1200 and $950 \mathrm{~cm}^{-1}$ ), can be found. The so-called "glue ratio", GR, that is the ratio between the area of the bands of cellulose $\left(1180-800 \mathrm{~cm}^{-1}\right)$ and the area of the bands of animal glue $\left(1690-1480 \mathrm{~cm}^{-1}\right)$, could be used to quantify the efficiency of the cleaning procedure. The GR value will increase appreciably if glue is removed. In our case, the GR value increases from $1.0 \pm 0.2$ (before cleaning) to $1.7 \pm 0.2,1.8 \pm 0.2$ and $2.3 \pm 0.2$ after cleaning with MR, LR and Gg, respectively. Therefore, the efficacy of the loaded gels for the removal of animal glue is evident, as also confirmed by pictures taken on glued samples before and after the cleaning tests, reported in Fig. 10.

Colorimetric tests have been performed on glued samples before and after the cleaning processes. The $\Delta \mathrm{E}$ values obtained from colorimetric measurements suggest that all the three hydrogels are effective in the removal of glue and, if present, also of products of cellulose degradation, significantly changing the color of samples. The differences in $\Delta \mathrm{E}$ between samples $(\mathrm{MR}=5.2 \pm 0.4 ; \mathrm{LR}=4.1 \pm 0.4 ; \mathrm{Gg}=8.0 \pm 0.5)$ are probably due to the slightly differences in gels efficacy in glue removal and, also, to the inhomogeneity of real paper samples. Hydrogels were also used for the removal of old starch paste from paper fragments belonging to a 20th century book (E. Antonini, "Guida alle esercitazioni di chimica biologica”, Ed. Universo, 1966). FTIR spectra acquired on paper before and after the cleaning process are reported in Fig. 9c. For comparison, the spectrum of a reference paper fragment (not covered with starch paste) is also reported. The spectrum of paper containing starch paste shows a characteristic band at $998 \mathrm{~cm}^{-1}$ [50], while cellulose has a maximum absorption at $1024 \mathrm{~cm}^{-1}$. The absorbance ratio between these two peaks [Abs(1024)/Abs(998)], called "starch ratio" (SR), is therefore a useful parameter to verify the efficiency of the cleaning 
Table 4

Diffusion coefficients in water and in hydrogels (D) of $10 \mathrm{kDa}$ and $40 \mathrm{kDa}$ FITC-dextrans and the relative mobile fractions (k).

\begin{tabular}{|c|c|c|c|c|}
\hline & \multicolumn{2}{|l|}{$10 \mathrm{kDa}$} & \multicolumn{2}{|l|}{$40 \mathrm{kDa}$} \\
\hline & $\mathrm{D}\left(\mu \mathrm{m}^{2} / \mathrm{s}\right)$ & $\mathrm{k}$ & $\mathrm{D}\left(\mu \mathrm{m}^{2} / \mathrm{s}\right)$ & $\mathrm{k}$ \\
\hline Water & $98^{a}$ & - & $70^{b}$ & - \\
\hline $\mathrm{Gg}$ & $89^{c}$ & $1^{\mathrm{c}}$ & $45^{c}$ & $1^{\mathrm{c}}$ \\
\hline LR & 22 & 1 & 5.3 & 0.89 \\
\hline MR & 4.7 & 0.76 & 1.5 & 0.18 \\
\hline
\end{tabular}

a Ref. [49].

b Ref. [50].

c Ref. [51].
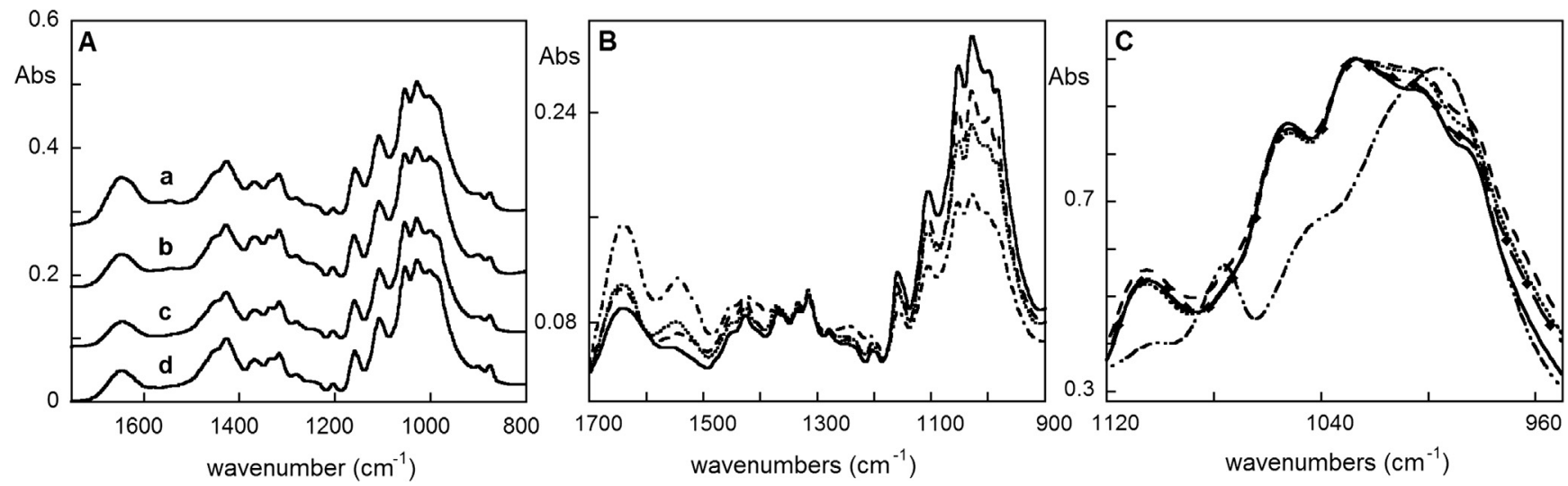

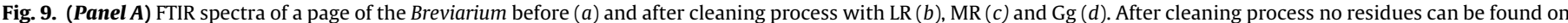

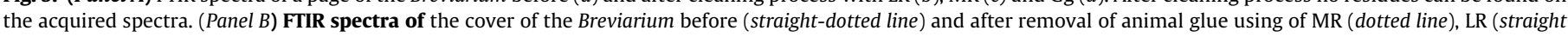

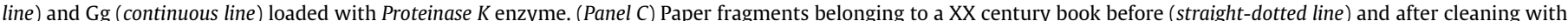
LR (straight line), MR (dotted line), Gg (continuous line). Also the spectrum of a paper fragment not covered with starch (straight dotted lines with triangles) is reported.

Table 5

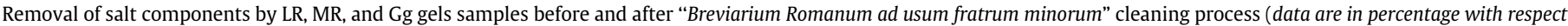
to the most intense peak).

\begin{tabular}{|c|c|c|c|c|c|}
\hline & Oxalic Acid & Ascorbic Acid & Lactic acid & Citric Acid & Succinic Acid \\
\hline LR, MR, Gg before cleaning & n.d. ${ }^{\mathrm{a}}$ & n.d. ${ }^{\mathrm{a}}$ & n.d. ${ }^{\mathrm{a}}$ & n.d. ${ }^{a}$ & n.d. ${ }^{\mathrm{a}}$ \\
\hline LR after cleaning & $27 \%$ & $6 \%$ & n.d. ${ }^{a}$ & $20 \%$ & n.d. ${ }^{a}$ \\
\hline MR after cleaning & $22 \%$ & n.d. ${ }^{a}$ & n.d. ${ }^{\mathrm{a}}$ & $10 \%$ & n.d. ${ }^{a}$ \\
\hline Gg after cleaning & $100 \%$ & nd & $10 \%$ & n.d. ${ }^{a}$ & $10 \%$ \\
\hline
\end{tabular}

\footnotetext{
a n.d: not determined.
}
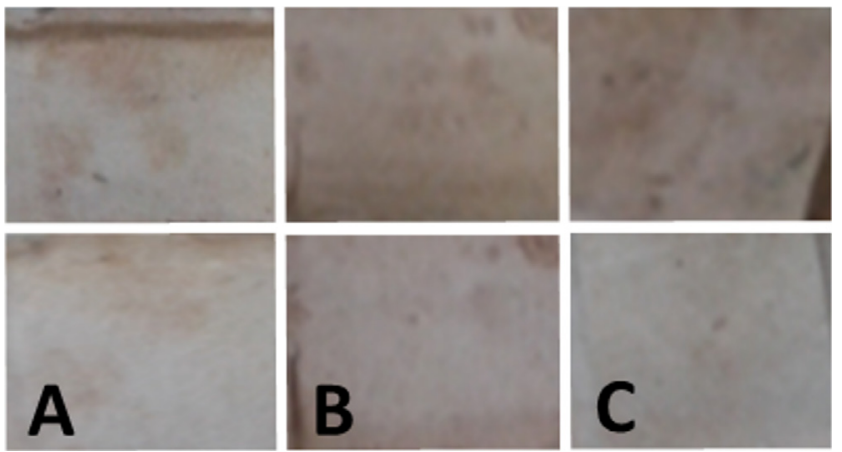

Fig. 10. Pictures of glued Breviarium samples before (upper panel) and after (lower panel) cleaning tests with Proteinase K-loaded hydrogels (A): MR; (B): LR, and (C): $\mathrm{Gg}$.

procedure. SR is $1.18 \pm 0.02$ for paper fragments not covered with starch, and decreases to $0.76 \pm 0.02$ for starch paste-coated paper. After cleaning tests, SR values decrease to $1.07 \pm 0.04,1.09 \pm 0.03$, and $1.14 \pm 0.03$, for MR, LR, and Gg. It is worth noting that the application of a water-loaded gel, without the enzyme, did not lead to a decrease of the SR value. Therefore, it can be concluded that all the tested formulations are efficient in performing the enzymatic removal from old starch from paper samples, as can be also seen in Fig. 9c. Pictures taken on paper samples before and after gel applications confirmed the analytical data reported above (Fig. 11). All of these results suggest that LR and MR porosity allows a release of a sufficient amount of water (or enzyme solution) that acts as a cleaning agent at the interface between paper and gel; the hydrogels characteristics (hydrophobicity, porosity) render them able to adsorb from the interface, degradation products (cellulose degradation products or hydrolyzed glue or starch). This is the reason because, even if the enzyme mobility into the gel is 10 times lower than in Gg [9], LR and MR gels containing enzymes are only slightly less able than $\mathrm{Gg}$ to remove natural glue from paper supports. To further characterize this interaction, optical microscope experiments have been performed following the diffusion of $\mathrm{MB}$ (colored compound that mimicks dust and cellulosic degradation products) from new paper sample, loaded with this dye, to LR or 

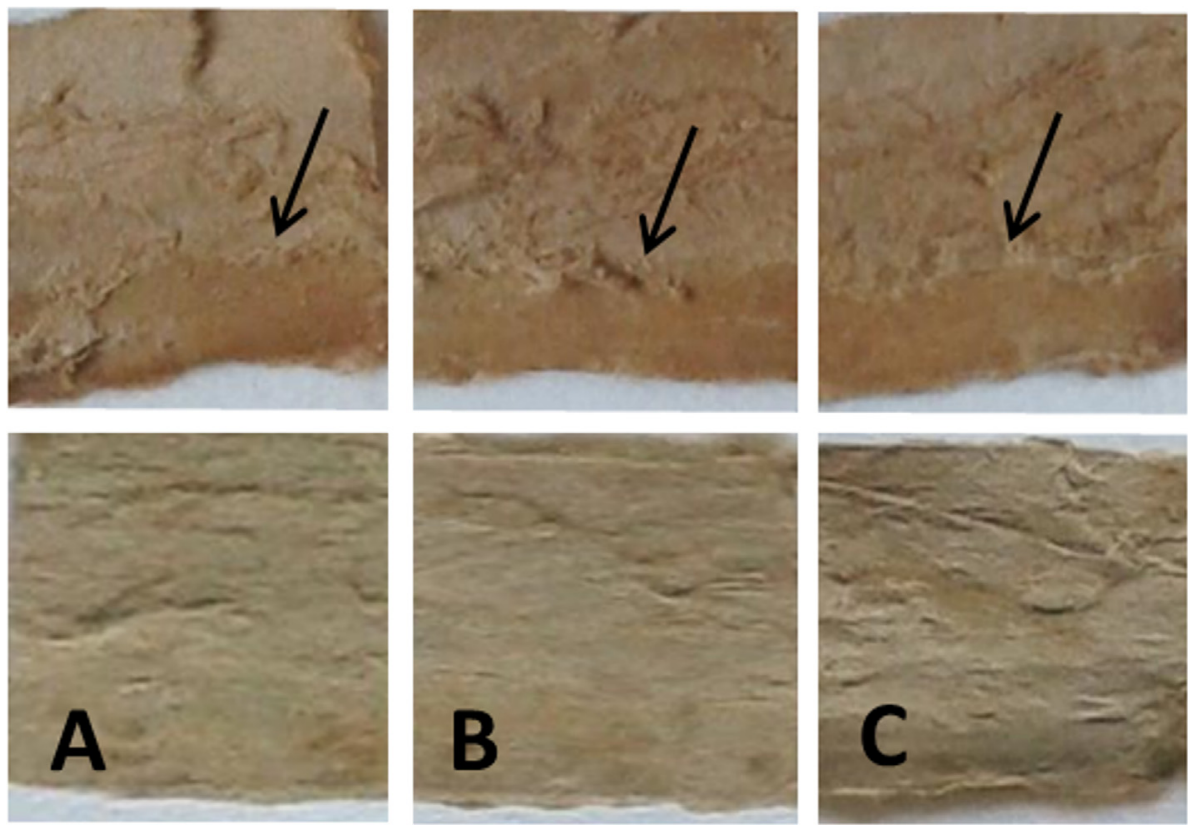

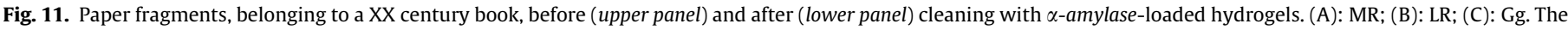
glued stripes (indicated by arrows) disappear after the cleaning process.

MR gel. During the experiment, MB has been absorbed by the gel diffusing inside it (as shown in Fig. S4). In Fig. 12, the length path, obtained for MB with respect to the LR or MR gel total height, as a function of time is reported. Fitting of this data by a square-root time dependent power law equation $\left(\mathrm{F}=\mathrm{kt}^{1 / 2}\right)$ demonstrate that MB diffusion with time from paper to gels follows Fick's law $[57,58]$. This means that, the variation in dimensions and chemico-physical properties of gel or paper are negligible and no anomalous behavior occurs, during cleaning process. It should be noted that the hydrogels are not inert sponges during the byproducts removal; HPLC analysis, indeed, show that the hydrogels properties play a key role in the selectivity and the extent of acids removal (Table 5).

Finally, it is interesting to underline, as shown in Fig. S5 that the surface put into contact with the gel appears clearer and that the depth of the "clearer" zone is dependent on the application time due to the interaction with the paper-gel and its ability to remove

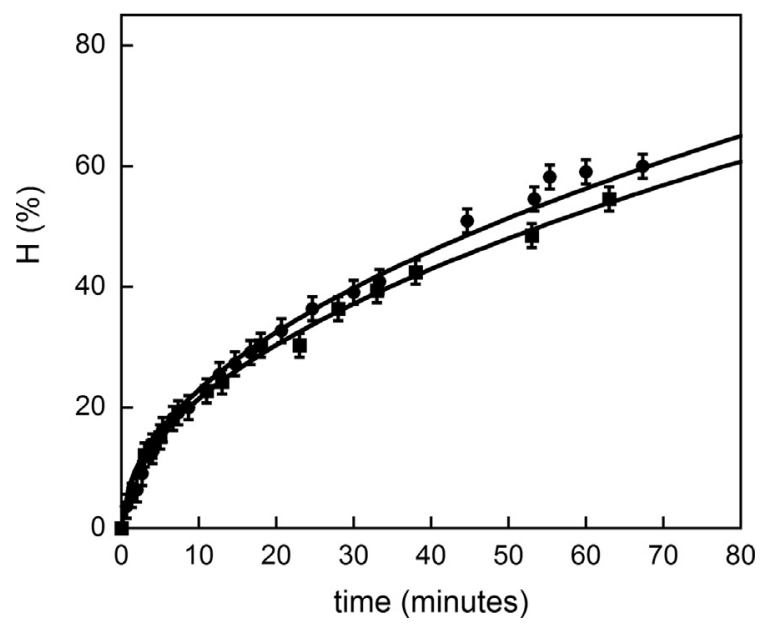

Fig. 12. Diffusion data during time of MB from paper to MR (full circles) and LR (full squares) gels-.H represents the height of the colored zone with respect to the total height of the gel, in percentage. the compounds. Indeed, after 20 min of gel application the "white" zone is about $1 / 5$ of the paper height, and increase to about $1 / 2$ after $60 \mathrm{~min}$ of cleaning. This means that, in principle, it is possible to determine the extent (in terms of depth) of the cleaning action. This possibility will be exploited in the future. Based on this evidences we can conclude that the water penetrates deep into the pores of the paper, but the cleaning effect is exercised by the gel into which the solubilized molecules diffuse.

\section{Conclusion}

In this work, we have tested the possibility of using two hydrogels, belonging to the class of highly retentive p(HEMA)PVP semi-IPN hydrogels, as innovative tools for the cleaning of paper artworks. This class of gels was yet presented [20,21]; however their interaction with paper samples as well as their efficiency to load active enzymes were not studied. Indeed, due to their highly retentive properties, they should be efficiently used as cleaning material for fragile and degraded paper artworks. To underline the advantages carried out by the use of these gels as paper cleaning tools, results obtained were compared to that obtained with a well-known cleaning gel that is Gellan gel $[2,6,9,10]$. In this contest, microstructural and rheology experiments indicate that these gels show a solid-like behavior, can be easily bent (this is not the case for Gellan gel) ensuring an uniform contact between the gel and the artwork, and at the same time they do no break and leave residues during the cleaning process. Interestingly, these gels could be reusable. Moreover, the amount of water released on the paper by these gels is about $40 \%$ less than Gellan gel, suggesting that they can be used on very fragile and water-sensitive artworks, and they allow a more localized cleaning process. At the same time, fluorescence microscopy results indicate that these hydrogels can be easily loaded with enzymes, very specific cleaning agents. Spectroscopic results indicate that the amount of water released by the gels is sufficient to ensure a satisfactory solubilization of products to be removed (glues, cellulosic byproducts) present on paper. The diffusional properties and the pore size of gels allow the absorption into the gels of the products removed from the paper during the cleaning process. 
Summarizing, the cleaning efficiency of the LR and MR gels are comparable or slightly less with respect to Gellan gel, allowing at the same time, a controlled cleaning process. Interestingly, HPLC results indicate that the gels are able to remove in different extent, several cellulosic byproducts. This findings could represent a starting point in designing gels with opportune properties (i.e., hydrophilicity of the network, pore size distribution and the mechanical properties) in order to obtain the most suitable hydrogel to remove specific patinas on paper, using simply the same gel preparation protocol and changing the $\mathrm{p}(\mathrm{HEMA}) / \mathrm{PVP}$ and water ratio used. Further studies are ongoing in developing this aspect.

\section{Acknowledgments}

CSGI and European Union (project NANOFORART, FP7-ENVNMP-2011/282816 and project NANORESTART, H2020-NMP-212014/646063) are gratefully acknowledged for partial financial support. Dr. Elena Romano and the Center of Advanced Microscopy, Biology Department of University of Rome "Tor Vergata" are acknowledged for support in FRAP measurements.

\section{Appendix A. Supplementary material}

Supplementary data associated with this article can be found, in the online version, at http://dx.doi.org/10.1016/j.jcis.2017.04.088.

\section{References}

[1] M. Strlič, J. Kolar, S. Scholten, Paper and durability, in: M. Strlič, J. Kolar (Eds.), Ageing and Stabilization of Paper, Ljubljana National and University Library, Ljubljana; Slovenia, 2005, pp. 1-23.

[2] C. Mazzuca, L. Micheli, M. Carbone, F. Basoli, E. Cervelli, S. Iannuccelli, S. Sotgiu, A. Palleschi, Gellan hydrogel as a powerful tool in paper cleaning process: detailed study, J. Colloid Interface Sci. 416 (2014) 205-211.

[3] M. Bicchieri, M. Monti, G. Piantanida, F. Pinzari, S. Iannuccelli, S. Sotgiu, L. Tireni, The Indian drawings of the poet Cesare Pascarella: non-destructive analyses and conservation treatments, Anal. Bioanal. Chem. 402 (2012) 1517 1528.

[4] A. Moropoulou, S. Zervos, The immediate impact of aqueous treatments on the strength properties of paper, Restaurator 24 (2003) 160-177.

[5] C. Isca, L. Fuster-López, D.J. Yusá-Marco, A. Casoli, An evaluation of changes induced by wet cleaning treatments in the mechanical properties of paper artworks, Cellulose 22 (2015) 3047-3062.

[6] L. Micheli, C. Mazzuca, A. Palleschi, G. Palleschi, Development of a diagnostic and cleaning tool for paper artworks: a case of study, Microchem. J. 126 (2016) $32-41$.

[7] A. Casoli, P. Cremonesi, C. Isca, R. Groppetti, S. Pin, i.N. Senin, Evaluation of the effect of cleaning on the morphological properties of the ancient papers, Cellulose 20 (2013) 2027-2043.

[8] A. Casoli, C. Isca, S. De Iasio, L. Botti, S. Iannuccelli, L. Residori, D. Ruggiero, S. Sotgiu, Analytical evaluation, by GC/MS, of gelatine removal from ancient papers induced by wet cleaning: a comparison between immersion treatment and application of rigid gellan gum gel, Microchem. J. 117 (2014) 61-67.

[9] C. Mazzuca, L. Micheli, E. Cervelli, F. Basoli, C. Cencetti, T. Coviello, S. Iannuccelli, S. Sotgiu, A. Palleschi, Cleaning of paper artworks: development of an efficient gel-based material able to remove starch paste, ACS Appl. Mater. Interfaces. 6 (2014) 16519-16528.

[10] C. Mazzuca, L. Micheli, R. Lettieri, E. Cervelli, T. Coviello, C. Cencetti, S. Sotgiu, S. Iannuccelli, G. Palleschi, A. Palleschi, A. how to tune a paper cleaning process by means of modified gellan hydrogels, Microchem. J. 126 (2016) 359-367.

[11] C. Mazzuca, G. Bocchinfuso, L. Micheli, F. Marini, M. Bevilacqua, G. Palleschi, A Palleschi, Rheoreversible hydrogels in paper restoration processes: a versatile tool, Chem. Cent. J. 8 (2014) 10-21.

[12] I. Schwarz, A. Blüher, G. Banik, E. Thobois, K.-H. Maurer, The development of a ready-for-use poultice for local removal of starch paste, Restaurator 20 (1999) 225-240.

[13] A. Blüher, U. Haller, G. Banik, E. Thobois, The application of carbopol poultices on paper objects, Restaurator 16 (1995) 234-247.

[14] D. Stulik and V. Dorge, Eds., Solvent gels for the cleaning of works of art: the residue question, Research in Conservation Series 4, in: V. Dorge (Ed.) The Getty Conservation Institute, Los Angeles, 2004. Getty Conservation Institute, los Angeles, CA, USA, 2004.

[15] L. Botti, A. Corazza, S. Iannuccelli, M. Placido, L. Residori, D. Ruggiero, S. Sotgiu, L. Tireni, A. Berzioli, C. Casoli, C. Isca, in: J. Bridgland, C. Antomarchi (Eds.) ICCCOM Lisbon 2011: Abstracts: 16th Triennial Conference, Lisbon, 19-23 September 2011. Almada: Critério, 2011, pp. 1-11.
[16] L. Micheli, C. Mazzuca, A. Palleschi, G. Palleschi, Combining a hydrogel and an electrochemical biosensor to determine the extent of degradation of paper artworks, Anal. Bioanal. Chem. 403 (2012) 1485-1489.

[17] P. Baglioni, N. Bonelli, D. Chelazzi, A. Chevalier, L. Dei, J. Domingues, E. Fratini, R. Giorgi, M. Martin, Organogel formulations for the cleaning of easel paintings, Appl. Phys. A 121 (2015) 857-868.

[18] N. Bonelli, D. Chelazzi, M. Baglioni, R. Giorgi, P. Baglioni, in: P. Dillmann, L. Bellot-Gurlet, I. Nenner (Eds.) Nanoscience and Cultural Heritage, Atlantis Press, Paris, 2016, pp. 283-311.

[19] P. Baglioni, D. Chelazzi, R. Giorgi, Nanotechnologies in the Conservation of Cultural Heritage - A Compendium of Materials and Techniques, first ed., Springer, Dordrecht, Netherlands, 2014.

[20] J.A.L. Domingues, N. Bonelli, R. Giorgi, E. Fratini, F. Gorel, P. Baglioni, Innovative hydrogels based on semi-interpenetrating p[HEMA]/PVP networks for the cleaning of water-sensitive cultural heritage artifacts, Langmuir 29 (2013) 2746-2755.

[21] J. Domingues, N. Bonelli, R. Giorgi, P. Baglioni, Chemical semi-IPN hydrogels for the removal of adhesives from canvas paintings, Appl. Phys. A 114 (2014) 705710.

[22] T.N. Blanton, T.C. Huang, H. Toraya, C.R. Hubbard, S.B. Robie, D. Louër, H.E. Göbel, G. Will, R. Gilles, T. Raftery, JCPDS-International Center for Diffraction Data round robin study of silver behenate. A possible low-angle x-ray diffraction calibration standard, Powder Diffr. 10 (1995) 91-95.

[23] T.G. Mezger, The Rheology Handbook: For Users of Rotational and Oscillatory Rheometers, 15th ed., Hannover, GmbH, Vincentz Network, 2006.

[24] C. Mazzuca, B. Orioni, M. Coletta, F. Formaggio, C. Toniolo, G. Maulucci, M. De Spirito, B. Pispisa, M. Venanzi, L. Stella, Fluctuations and the rate-limiting step of peptide-induced membrane leakage, Biophys. J. 99 (2010) 1791-1800.

[25] D. Axelrod, D.E. Koppel, J. Schlessinger, E. Elson, W.W. Webb, Mobility measurement by analysis of fluorescence photobleaching recovery kinetics, Biophys J. 16 (1976) 1055-1069.

[26] J. Yang, K. Kohler, D.M. Davis, N.J. Burroughs, An improved strip FRAP method for estimating diffusion coefficients: correcting for the degree of photobleaching, J. Microscopy 238 (2010) 240-253.

[27] I. Kasic, V. Matejec, M. Chomat, M. Hajer, Optical fibers for optical sensors, in: F. Baldini, A.N. Chester, J. Homola, S. Martellucci (Eds.), Optical Chemical Sensors, Springer Science \& Business Media, Berlin GMBH, 2006, pp. 59-76.

[28] A. Jobbagy, K. Kiraly, Chemical characterization of fluorescein isothiocyanateprotein conjugates, Biochem. Biophys. Acta. 124 (1966) 166-175.

[29] M. Strlič, J. Kolar, D. Kočar, T. Drnovšek, V.S. Selih, R. Susič, B. Pilhar, What is the $\mathrm{pH}$ of the alkaline paper?, Preserv Sci. 1 (2004) 35-47.

[30] B. Hammouda, D.L. Ho, S. Kline, Insight into clustering in poly[ethylene oxide] solutions, Macromolecules 37 (2004) 6932-6937.

[31] R.A. Hule, R.P. Nagarkar, A. Altunbas, H.R. Ramay, M.C. Branco, J.P. Schneider, D. J. Pochan, Correlations between structure, material properties and bioproperties in self-assembled $\beta$-hairpin peptide hydrogels, Faraday Discuss. 139 (2008) 251-264.

[32] E.M. Saffer, M.A. Lackey, D.M. Griffin, S. Kishore, G.N. Tew, S.R. Bhatia, SANS study of highly resilient poly[ethylene glycol] hydrogels, Soft Matter 10 (2014) 1905-1916.

[33] Z. Yang, Y. Hemar, L. Hilliou, E.P. Gilbert, D.J. McGillivray, M.A.K. Williams, S. Chaieb, Nonlinear behavior of gelatin networks reveals a hierarchical structure, Biomacromol 17 (2016) 590-600.

[34] B. Hammouda, D.L. Ho, Insight into chain dimensions in PEO/water solutions, J. Polym. Sci., Part B: Polym. Phys. 45 (2007) 2196-2200.

[35] B. Hammouda, SANS from polymers-review of the recent literature, Polymer Rev. 50 (2010) 14-39.

[36] M. Shimizu, T. Brenner, R. Liao, S. Matsukawa, Diffusion of probe polymer in gellan gum solutions during gelation process studied by gradient NMR, Food Hydrocoll. 26 (2012) 28-32.

[37] E.R. Morris, K. Nishinari, M. Rinaudo, Gelation of gellan - a review, Food Hydrocolloids 28 (2012) 373-411.

[38] H. Yoshida, M. Takahashi, Structural change of gellan hydrogel induced by annealing, Food Hydrocoll. 7 (1993) 387-395.

[39] Y. Yuguchi, M. Mimura, H. Urakawa, S. KitamuraS, S. Ohno, K. Kajiwara, Small angle X-ray characterization of gellan gum containing a high content of sodium in aqueous solution, Carbohyd. Polym. 30 (1996) 83-93.

[40] Y. Yuguchi, H. Urakawa, S. Kitamura, I. Wataoka, K. Kajiwara, in: K. Nishinari (Ed.), Physical Chemistry and Industrial Application of Gellan Gum, vol. 114, Springer, Berlin, Heidelberg, 1999, pp. 41-47.

[41] S. Kasapis, R. Abeysekera, N. Atkin, M. Deszczynski, J.R. Mitchell, Tangible evidence of the tranformation from enthalpic to entropic gellan networks at high levels of co-solute, Carbohyd. Polym. 50 (2002) 259-262.

[42] T. Canal, N.A. Peppas, A. correlation between mesh size and equilibrium degree of swelling of polymeric networks, J. Biomed. Mater. Res. 23 (1989) 11831193.

[43] S. Spoljaric, A. Salminen, N.D. Luong, J. Seppälä, Stable, self-healing hydrogels from nanofibrillated cellulose, poly[vinyl alcohol] and borax via reversible crosslinking, Eur. Polym. J. 56 (2014) 105-117.

[44] R. Suriano, G. Griffini, M. Chiari, M. Levi, S. Turri, Rheological and mechanical behavior of polyacrylamide hydrogels chemically crosslinked with allyl agarose for two-dimensional gel electrophoresis, J. Mech. Behav. Biomed. Mater. 30 (2014) 339-346.

[45] J.K. Armstrong, R.B. Wenby, H.J. Meiselman, T.C. Fisher, The hydrodynamic radii of macromolecules and their effect on red blood cell aggregation, Biophys. J. 87 (2004) 4259-4270. 
[46] J. Larkin, R.Y. Henley, M. Muthukumar, J.K. Rosenstein, M. Wanunu, Highbandwidth protein analysis using solid-state nanopores, Biophys. J. 106 (2014) 696-704.

[47] P.A. Perry, M.A. Fitzerald, R.G. Gilbert, Fluorescence recovery after photobleaching as a probe of diffusion of starch systems, Biomacromol 7 (2006) 521-530.

[48] Y. Cheng, R.K. Prud'homme, J.L. Thomas, Measurement of forces between galactomannan polymer chains: effect of hydrogen bonding, Macromolecules 35 (2002) 8111-8121.

[49] J.R. Lawrence, G.M. Wolfaardt, D.R. Korber, Monitoring diffusion in biofilm matrices using confocal laser microscopy, Appl. Environ. Microbiol. 60 (1994) $1166-1173$.

[50] A. Savchenko, C. Vieille, S. Kang, J.G. Zeikus, Pyrococcus furiosus $\alpha$-amylase is stabilized by calcium and zinc, Biochemistry 41 (2002) 6193-6201.

[51] P. Calvini, A. Gorassini, FTIR-deconvolution spectra of paper documents, Restaurator 23 (2002) 205-221.

[52] V. Librando, Z. Minniti, S. Lorusso, Ancient and modern paper characterization by FTIR and Micro-Raman spectroscopy, Conserv. Sci. Cult. Heritage 11 (2011) 249-267.
[53] J. Lojewska, P. Miscowiec, T. Lojewski, L.M. Proniewicz, Cellulose oxidative and hydrolytic degradation: in situ FTIR approach, Polym. Degrad. Stab. 88 (2005) 512-520.

[54] T. Lojewski, K. Zieba, A. Knapik, J. Bagnuk, A. Lubanska, Evaluating paper degradation progress. Cross-linking between chromatographic, spectroscopic and chemical results, Appl. Phys. A Mater. Sci. Process. 100 (2010) 809-821.

[55] S. Krimm, J. Bandekar, Vibrational spectroscopy and conformation of peptides, polypeptides, and proteins, Adv. Protein Chem. 38 (1986) 181-364, http://dx doi.org/10.1016/S0065-3233(08)60528-8.

[56] H. Maekawa, G. Ballano, C. Toniolo, N.-H. Ge, Linear and two-dimensiona infrared spectroscopic study of the Amide I and II modes in fully extended peptide chains, J. Phys. Chem. B 115 (2011) 5168-5182.

[57] K. Park, W.S.W. Shalaby, H. Park, Biodegradable drug delivery systems, in: Biodegradable Hyrdrogels for drug Delivery, Technomic Publishing Company Inc., Lancaster, Pennsylvania, USA, 1993, pp. 189-226.

[58] C.-C. Lin, A.T. Metters, Hydrogels in controlled release formulations: network design and mathematical modeling, Adv. Drug Deliv. Rev. 58 (2006) 13791408. 